\title{
A Preliminary Study of International Student Perceptions of Online VERSUS FACE-TO-FACE EDUCATION
}

\author{
Lynn A. Fish and Coral R. Snodgrass
}

Professors of Management, Richard J. Wehle School of Business, Canisius College, Email: fishl@canisius.edu and snodgras@canisius.edu.Professor Fish is the corresponding author.

\begin{abstract}
As higher education institutions continue to integrate online education into their curricula, different cultural perspectives on the value of online versus face-to-face education will undoubtedly have an impact on continued proliferation. For example, some nations believe online education is inferior to traditional education and will not accept credentials acquired through online education (Asunka, 2008). Unfortunately, research on this topic is currently lacking. Similar to another study of business students perceptions (Fish \& Snodgrass, 2014), this project proposes to study a sample of international students to examine differences in perceptions between online and face-to-face education. Perceptions are explored with respect to student characteristics (such as age, gender or familiarity with online courses) and program characteristics (such as the amount of rigor or the ease of cheating).
\end{abstract}


Results have implications for administrators and instructors especially as US institutions endeavor to attract new international students to their online programs.

Keywords: International Student Perceptions, Online, Face-to-face

\section{LITERATURE REVIEW: DIMENSIONS OF DIFFERENCE}

A recent study by the Babson Survey Research Group highlights the increase in online education throughout the higher education system (Allen \& Seaman, 2013). While academic administrators believe that learning outcomes through online education are the same or superior to those in traditional FTF classrooms (Allen \& Seaman, 2013), critics argue that due to intrinsic differences, online education does not replicate the learning that occurs in the traditional classroom (Bejerano, 2008). With this continued proliferation and evolving technology, research on student perceptions in the online learning environment continues (e.g. Allen \& Seaman, 2013; Perreault, Waldman, Alexander \& Zhao, 2008; Tanner, Noser, and Langford, 2003; Tanner, Noser, Fuselier \& Totaro, 2004-1; 2004-2; Tanner, Noser, Totaro \& Birch, 2006; Tanner et al., 2009). Several studies cite the need to explore cultural differences between online and FTF education student perceptions as these another potential barrier to online education (Fish \& Snodgrass, 2014; Lin, Liu, Lee \& Magjuka, 2010; Olesova et al., 2011). With this in mind, we propose to expand our previous study (Fish \& Snodgrass, 2014) to explore international perceptions of online versus FTF education.

What do we know about other cultural perceptions about online education now? Studies to explore this new medium of information transfer are emerging. A nation's culture directly affects the students' engagement, relations, and perceived benefits from online education (Lee, Becker \& Nobre, 2012). Each culture has its own way of processing information, learning, instructing and solving problems, and therefore, a student's acceptance of learning through an online medium could be 
a function of culture (Lee et al., 2012). Added to this is the notion that different cultures differ across regional, linguistic and natural boundaries (Lee et al., 2012). As education methods change to incorporate more online elements, educators and administrators need to understand these perceptual differences to be successful. Some countries, such as China and India, appear to be attractive destinations for online education. However, other countries - particular African countries, perceive online learning as second-rate to FTF education (Asunka, 2008). These nations actually enacted policies that do not recognize foreign credentials obtained through online courses due to quality and accreditation issues (Asunka, 2008).

In a review of some current research on this theme, two streams of literature emerged: student-centered and program-centered. Student centered studies concentrate on differences such as age, gender or familiarity with online courses. Program characteristics address such issues as academic rigor, ease of cheating, and course academic requirements. Added to each of these literature streams are the different student and program characteristics related to specifically to differences in culture and how different cultures respond.

\section{Student Characteristics}

Student characteristics - age, major/level, gender, previous experience with an educational method, student motivation and commitment, all impact upon a student's perception of online education. In a traditional FTF classroom, instructors recognize and react to emotional states (facial expressions, gestures, eye contact and speech) and individual student differences (maturity and experience) and modify their lessons to help students toward positive learning experiences (Reilly, Gallager-Lepak $\&$ Killion, 2012). However, an online course does not allow instructors to modify the course in 'real' time and those factors may impact upon students' perceptions in the online versus the FTF environment.

Age. While one research stream indicates that age impacts upon students' perceptions of online learning (Tanner et al., 2004-1; 2004-2), 
another study indicates that age does not play a factor in student perceptions for undergraduate students and highlights the difference between adult students (21and older) with a more favorable perception of online learning than younger students (Tanner et al., 2003). To our knowledge, age and cultural implications have not been explored; however, many researchers note that younger students regardless of their culture appear to be more technologically savvy and adaptable to different cultures (Lee et al., 2012). Are younger cultures more inclined to accept online courses than older members? As people age, do they accept online courses more readily?

Major/ Level. Several studies have explored perceptual differences by major and educational level. Some studies note differences between student perceptions for business versus non-business students (Tanner et al., 2004-1; 20004-2) and graduate versus undergraduate nursing student (Billings, Skiba \& Connors, 2005). In the nursing study, findings indicated that graduate students spent more time on their courses, needed more instructor attention and found faculty availability to be an issue compared to undergraduates. In criminal justice studies, students who have never taken an online course have different perceptions of online learning than those who have (Dobbs et al., 2009). In our previous study of business students, undergraduates and graduates did not differ with respect to their perception of online versus FTF environments for students with and without online experience and disliked the instructor interaction (Fish \& Snodgrass, 2014). Graduates tended to dislike the self-directed online environment slightly more than their undergraduate counterparts, and graduates were slightly more hesitant to accept online as a viable alternative to FTF. All of these studies included American students studying in the U.S. Are results for other cultures mixed or do other cultures respond differently by major and academic level?

Gender. With respect to gender differences, research results differ with some studies indicating that gender does not play a factor in student perceptions for undergraduate students (Tanner et al., 2003; Fish \& Snodgrass, 2014), while others indicate a difference (Tanner et al., 
2004-1; 2004-2). In a more recent study, Internet competencies tend to be significant and favor males (Tekinarslan, 2011). In our study, the only gender differences that existed were in the traditional FTF students where undergraduate females felt online courses were acceptable and males were undecided (Fish \& Snodgrass, 2014) and online graduate males were significantly happier and felt online was appropriate than their female counterparts (Fish \& Snodgrass, 2014). Do other cultures with different gender roles perceive online education differently?

Previous Experience. Learning theory implies that the more someone is exposed and uses a particular method or technology, the better and more adept they become. Students with prior online experience perceived online courses more favorably than those without prior experience (Tanner et al., 2003). As the number of online courses increases, the students' acceptance of online courses increases as well; however, at least 5 online courses are necessary for student to perceive that they learn more in the online environment than FTF and student's perceive that faculty have higher expectations (Dobbs, Waid \& del Carmen, 2009). A student's belief in his or her own abilities to perform a given task in the online environment, also known as self- efficacy, increases as a student's Internet usage frequency increases and are highly related to their prior computer and Internet experiences (Tekinarslan, 2011).

Students without online experience perceive faculty as having low student expectations for students in the online environment, but for students with online experience, especially as the number of online courses increases, students' perceptions of faculty as having higher expectations increases (Dobbs, Waid \& del Carmen, 2009). Initial studies on requirements for students prior to enrollment favored using training or tutorials (Perrault, Waldman, Alexander \& Zhao, 2002); however, more recent studies indicate that today's online students felt they are adequately prepared for online education without prior training (Perreault et al., 2008). Studies evaluating student's perceptions of the continued proliferation of online courses demonstrate an increasing acceptance 
of online as being equal to or better than FTF (Perreault et al., 2008; Mortagy \& Boghikian-Whitby, 2010) particularly as a student take more online courses (Dobbs et al., 2009; Mortagy \& Boghikian-Whitby, 2010; Perreault et al., 2008). Similarly, our survey instrument indicated that as students take more courses, their perceptions of the online environment improves, students felt that online was more difficult than traditional classes and significantly more difficult to cheat online, and interaction with other students improved (Fish \& Snodgrass, 2014). Is this the case for international students? Does their satisfaction with the online environment increase as more online classes are taken?

Student Motivation and Commitment. With regard to student motivation, results are mixed as some studies indicate that the online environment increases student motivation and self-esteem (Kearlsey, 1996) and others, including our study, indicate that the online environment offers low motivation for students to learn (Maltby \& Whittle, 2000; Fish \& Snodgrass, 2014) with retention issues (Carr, 2000) and low student satisfaction (Kenny, 2003; Muilenburg \& Berge, 2005). Students perceive online learning to be more time consuming particularly with respect to class activities and homework assignments (Perreault et al, 2008: Dobbs et al., 2009). In our study, online students were indifferent to time demands (Fish \& Snodgrass, 2014). In the international market, are students indifferent to time demands, or due to time zones, do the time requirements become more of a barrier to student learning and interaction with others?

Cultural Student Differences. In addition to the age, major, level, gender, previous experience, motivation and commitment differences between students, there are general differences in the way that different cultures address different student learning styles and requirements. For example, Chinese participants feel that they are less opinionated and critical than their U. S. counterparts (Thompson \& Ku, 2005). Eastern students preferred to have more direction from their instructors than Western students who prefer student interaction (Liang \& McQueen, 1999). US students tend to work more independently than Chinese (Lin et 
al., 2010). Added to these additional complexities, language competencies magnify cultural issues when completing an online course (Ku \& Lohr). Our initial study did not explore the cultural issues respective to online student issues. Does the nationality of a student impact upon his preferred learning environment? Does the nationality of a student impact upon his ability to learn online?

\section{Program Characteristics}

Clearly, the student satisfaction is partially a function of the student characteristics in the online course; however, certain program characteristics impact the learning experience. Distance education barriers include faculty, organization and course structure, physical distance between members, difficulties in dealing with media, time constraints, lack of background knowledge or distance education experience, lack of technology skills, and low interactivity with the communication process (Olesova, Yang \& Richardson, 2011). While, current domestic research on these topics produced mixed results as well, as the educational world becomes more global, cultural issues will play a role in learning.

Cultural Program Issues. In a seminal article, Hofstede (1986) proposed a framework to study cross-cultural communications by four dimensions: power distance (social status and its impact upon learning), individualism-collectivism (tendency of individuals to act as individuals or as part of a group), un-certainty avoidance (degree to which individuals accept uncertain situations and results), and masculinity-femininity (degree to which society prefers maximization outcomes versus quality of life improvements). For example, several studies explored differences between individualistic and collective societies' perceptions (Lin et al., 2010; Hornik \& Tupchiy, 2006). In contrast to Hofstede's framework, which critics cite as lacking fluidity, the 'flexible' approach to educational design recommends developing courses that are capable of catering to the diverse cultural perspectives, rather than simply containing 'predetermined content'(Collis, 1999). Several researchers propose developing the key aspects of the course contingent upon the cultural dimensions of 
the course and are flexible enough to allow students and instructors to choose their own learning and teaching styles as the course progresses (Collis, 1999; Henderson, 1996; McLoughlin \& Oliver, 2000).

Cultural differences related to course design, delivery and technological medium may impact upon the ability to transport it to a different culture (Lee et al., 2012). In an online MBA study, course cultural differences were noted for assessment (exam-oriented (collective; Eastern societies) versus process-oriented (individualistic; Western societies), instruction/interaction (lecture versus conversation; structure (Eastern) vs. less structure (Western); deductive versus inductive learning), asynchronous versus synchronous communication (lack of visual cues causing communication barriers, scheduling issues for cross-cultural collaboration, time zone differences), collaboration (collectivism vs. individualism; masculinity versus femininity), case learning (lack of global cases, lack of local issues for international students, lack of international experience of online instructors), academic conduct (discrepancies between US and other countries' rules of academic conduct), and language (barriers in reading, writing and communication) (Lin et al., 2010). The MBA study noted that appropriate cross-cultural training is needed for instructors so they can design appropriate courses, and the international students being educated through U.S. systems need additional support to reduce cultural language and learning barriers (Lin et al., 2010).

Several studies explored cultural program differences between two or more cultures. For example, the U.S. instruction style leans toward a learner-centered, process-oriented style with interaction and participation as critical components, while Eastern instruction tends to be lecture-centered with an emphasis on exams (Lin et al., 2010; Zhang, 2007). Russian and U.S. students notice differences in assessment styles (Lin et al., 2010). Eastern educational systems tend to be based upon memorization of material and the instructor as the center of the educational process, where the Western education system focused on the process and discussion between classmates and the instructor (Lin et al., 
2010). Cultural differences within team work between virtual teams and student perceptions exist (Olesova et al., 2011). Eastern students tend to exhibit face-saving, modest personalities in group work and prefer group work, while American students appear to be independent, assertive and competitive attitude that dominates group work (Lin et al., 2010).

Course Organization. Flexibility and convenience are the most common reasons students indicate as to why they take online courses (Armstrong, 2011; Horspool \& Lange, 2012; Leasure et al., 2000; Perreault et al., 2008). However, students perceive the course organization particularly the structure of the learning environment and the nature of online assessment, as key to student learning and success (Armstrong, 2011). Studies report student distress with online learning with ambiguous instructions (Merisotis \& Olsen, 2000; Perreault et al., 2008) as students want concise, specific directions on everything (Armstrong, 2011). Eastern students have an even higher affinity for structured courses than Western students (Lin et al., 2010). Research suggests that it is important to invest in research-based validated online frameworks and benchmarks in planning, designing, delivering and assessing online education which depends on an effective course design that uses a student-centered model (Mortagy \& Boghikian-Whitby, 2010). Added to this complicated environment are the cultural differences that exist between Western assessments, which are process-oriented, versus Eastern assessments, which are exam-oriented (Lin et al., 2012). As another example of differences in course organization expected in different cultures, Ghana students responded negatively to online constructivist teaching approaches such as asynchronous discussions and ill-structured project-based learning activities (Asunka, 2008). Do different cultures expect and perceive online course structure differently?

Academic Rigor. With respect to academic rigor, results are mixed as some studies indicate that online is more rigorous than FTF (Dobbs et al., 2009), while others indicate that FTF is more rigorous than online (Armstrong, 2011). In sub-Sahara Ghana, students perceived collaborative 
online learning as complex, more demanding and time-consuming than in a FTF environment (Asunka, 2008). In our previous study, online students disliked the academic rigor associated with working independently (Fish \& Snodgrass, 2014). Do different cultures perceive differences in the academic rigor associated with online courses?

Program Quality. Chief academic officers claim that online learning is now of the same quality as traditional courses and that online offerings allow institutions to better serve students' needs (Allen \& Seaman, 2013). However, with respect to student perceptions of quality, research results are again mixed with some studies indicating students perceive the quality to be better and more fun with a technology-enhanced online learning environment (Fjermestad, Hiltz, \& Zhang, 2005; Hannay \& Newvine, 2006; Parker, 2003) and other studies (in Ghana) indicating the opposite as students held the view that online learning offered no advantage over FTF (Asunka, 2008). Similarly, online experience factors into quality perceptions as students who took an online course disagree with the statement that the quality of online courses was lower than FTF, while those who had not taken an online course felt online quality was lower (Dobbs et al., 2009). One study noted that in some African countries perceive online learning as second-rate to FTF education (Asunka, 2008). Do different cultures value online programs differently than FTF ones?

Academic Integrity. Faculty and students approach the online environment results cautiously as rumors surrounding cheating abound. The general feeling is that since the threat of being caught is low, students may be inclined to cheat more online than in the traditional classroom. While most criminal justice students indicate that they never cheated, a comparison of FTF and online student perception indicates that cheating is more common in online courses than FTF (Lanier, 2006). Students with higher gpa's, females, married and older students are less inclined to cheat (Lanier, 2006). In our previous study, FTF and online students felt cheating is easier online than in the traditional classroom (Fish \& 
Snodgrass, 2014). Do different cultures perceive online cheating to be more, the same or less rampant than in the FTF classroom?

Communication Mechanisms. Communication is shaping students' perceptions and approaches to learning as communication speed and consistency are relevant (Armstrong, 2011). Again, mixed messages result as some studies indicate online courses enhance learner participation and interactivity (Fredericksen, Pickett, Shea, Pelz, \& Swan, 2000; Maeroff, 2004; Wang \& Morgan, 2008), and others highlight student distress (Hara \& Kling, 2003) or general feeling of 'disconnect' due to the lack of FTF interactions (Stodel, Thompson \& MacDonald, 2006). In our previous study, online students disliked the student interaction compared to FTF classes (Fish \& Snodgrass, 2014). Similarly, the inability to interact through posing questions, sharing opinions, engaging in dialogue, or a sense of belonging to a group influence student perceptions as to how well they perform in an online class (Picciano, 2002; Song, Singleton, Hill \& Koh, 2004). Several online studies indicate that students report communication issues with other students (Horspool \& Lange, 2012) along with a general unwillingness of other online learners to participate in group activities (Dirkx \& Smith, 2004; Maeroff, 2004). Online students report meeting with their peers less often than FTF students and form fewer study groups than FTF students (Horspool \& Lange, 2012). In the online environment, a lack of visual cues causing communication barriers, scheduling issues for cross-cultural collaboration and time zone differences, add another barrier to the educational process (Lin et al., 2010). Also differences exist in the way cultures communicate and control situations (Lin et al., 2010). In a recent study of an online MBA program, the international online learners felt 'marginalized' by their American counterparts who essentially 'took over' the learning experience; however, the international students did not feel that this control negatively impacted upon their communication or collaboration in learning (Lin et al., 2010). Do other societies than the U.S. perceive the online interaction with others to be significantly different? 
Faculty Involvement. A positive correlation between the degree of social presence and perceived learning and perceived quality of the instructor exists (Richardson \& Swan, 2003). When faculty are perceived as missing from the educational conversation, students perceived the course quality as poor (Armstrong, 2011). Again, mixed results with respect to student communication with the online instructor exist. Some studies indicate that online interaction with the instructor is equal or even more positive than FTF (Boyd, 2008), and online students perceive faculty as having high expectations and are available to communicate, interact and provide feedback (Mortagy \& Boghikian-Whitby, 2010). But other studies indicate FTF student perceive greater interaction than online students (Fish \& Snodgrass, 2014; Wuensch, Aziz, Ozan, Kishore \& Tabrizi, 2008; Wang \& Morgan, 2008), while another study indicates no significant difference between online and FTF interaction with the instructor (Horspool \& Lange, 2012). Do other cultures perceive the instructor interaction online to be more, the same or less than in the FTF environment?

Technologies. While online education offers greater access to learning resources (Sener \& Stover, 2000), it requires skills such as maintaining a stable or wireless Internet connection, Internet navigation, searching for relevant information, using multimedia applications, uploading a file to an asynchronous or synchronous conferencing system, writing and publishing on the Internet, opening a web browser or even publishing on a web-site (Tekinarslan, 2011). With respect to technical issues, both online and FTF students appear technically well-equipped to take online courses as less than $40 \%$ reported significant communication issues (Hospool \& Lange, 2012). Unfortunately, faculty weak in understanding technology appear to utilize technology in a way that creates confusion (Armstrong, 2011). Students utilize nonacademic resources (e.g. Google) more readily (due to familiarity) than academic resources (cumbersome and difficult to navigate) in completing assignments (Armstrong, 2011). Most used and valued elements include accessing unit information, accessing lecture/lab notes, interacting with unit learning resources, 
reading online discussions, contacting lecturers/tutors and submitting assignments online (Palmer \& Holt, 2010). Students indicated receiving feedback on assignments and reviewing unit progress as needing attention by the provider (Palmer \& Holt, 2010). Students perceived video modules, quizzes and the textbook as valuable to the learning environment regardless of online or FTF (Horspool \& Lange, 2012). Instant messaging may be used as a technique to increase dialogue and reduce distance between students in an online course (Wang \& Morgan, 2008). In our study, online students perceived homework, discussion and videos as adding the most to their understanding, while instructor lectures and in-class sessions decreased their understanding; however, FTF students perceived instructor lectures, interaction with others and in-class sessions increased their understanding (Fish \& Snodgrass, 2014). Do international students respond differently to the technology and technological skills required in the online environment than U.S. students?

\section{Salient Conclusions for Our Study}

Obviously our literature review is not a comprehensive review of literature in this area, however, it serves to clearly indicate the ambiguity that exists in the debate between online and FTF education. Student satisfaction research indicates mixed views as some studies suggest students view each equally (Fowler, 2005; Topper, 2007; Horspool \& Lange, 2012), while others show a preference to FTF over online environments (Mullen \& Tallent-Runnels 2006), and others show a higher satisfaction for online learning (Connolly, MacArthur, Stansfield \& McLelan, 2007). These studies differ in the size (small, medium, large universities), audience (e.g. scientific versus social sciences, business versus nonbusiness, and graduate versus undergraduate), method of research (e.g. interview, survey), completion at a large university or in a public forum (Tanner et al., 2003; Tanner et al., 2004-1; 2004-2; Tanner et al, 2006; Tanner et al., 2009) or a small environment (e.g. Armstrong, 2011), or in non-business fields (e.g. Dobbs, Waid, \& delCarmen, 2009; Lanier, 2006; Leasure, Davis \& Theivon, 2000; Reilly et al., 2012; Tekinarslan, 
2011; Wang \& Morgan, 2008). Therefore, as our previous preliminary results highlighted, the context of the study may be an important factor to consider in interpretation of the survey results.

A significant portion of the research we uncovered is currently over 5 years old. But as technology progresses, perceptions and online education will change as well (Mortagy \& Boghikian-Whitby, 2010; Perreault et al., 2008), including in the international market (Lee et al., 2012).

We conducted our study at a mid-sized, Jesuit, Catholic, business school with a focus on teaching. The research focus lies in uncovering international student perceptions where FTF class sizes average 17 students. Online education is a growing educational method; however, not all students have experienced this medium (Allen \& Seaman, 2013). Based upon the literature, the intent of this research is to explore the international students' perceptions of the online experience for those who have experienced and those who have never experienced online as well as graduate versus undergraduate business student online perceptions at a teaching university. Specifically, this research seeks to explore: Why do international students at a teaching university choose online or traditional FTF classes? What are the factors that motivate each group? Which medium do international students at a teaching university prefer? Why? Similarly, are there differences between undergraduates and graduates in these perceptions? Are there differences between men and women's perceptions? Do student's perceptions change as they take more online courses? Specific perceptions to research include perceptions of academic rigor, self-directed learning, motivation, interaction between students and the instructor, discipline required, cheating, flexibility, time investment, costs, and teaching activities preferred. Theoretically, students should perceive the environments equally and not favor either traditional or online education. 


\section{METHODOLOGY}

Based upon the above research and insight into the online versus FTF learning environments, the instructors designed a survey to test student perceptions of experience levels, gender, academic rigor and self-directed learning, motivation, interaction between students and the instructor, discipline, ability to cheat, flexibility, time investment, cost investment, activities, activity preferences, and why students choose the online environment (See Appendix A). At an AACSB accredited, Jesuit, Catholic University in the northeast, the international population was surveyed using an online survey created through Checkbox. This survey was previously administered to the domestic population (Fish \& Snodgrass, 2014) with the only deviations including questions regarding the participants' nationality and age.

Background information gathered included class level, gender, age, nationality, and online experience. Students who experienced at least 1 online course completed Section A ("Online"), while students who had never taken an online course completed Section B ("Traditional FTF”). Sections A and B had corresponding questions, but Section A statements were specific to "I found" versus Section B statements were "I perceive". The last questions in each section asked the student if they would prefer the opposite environment, their emotional happiness with the learning environment, and whether online courses were appropriate for the institution. For students with online experience, the last question inquired as to why they chose to take an online course. For students without online experience, the survey included an open-ended question inquiring 'why not'.

The survey was administered during the middle of the semester over a 3 week period. To increase participation, the survey was sent out 3 times over the 3 weeks period. Student participation was completely voluntary. For comparison purposes with the American student perceptions, one section from the previous study (Fish \& Snodgrass, 2014) was used as no international students were in that class. The section consisted of 
undergraduates enrolled in a junior-senior level required operations management course.

\begin{abstract}
ANALYSIS
In total $\mathbf{1 7}$ international students participated in the survey, with 10 undergraduates ( 3 freshman, 1 sophomore, 4 juniors and 2 seniors) and 6 graduates. 6 participants were male while 11 were female. Nationalities included over 12 completely different countries from around the world (as shown in Appendix A, where information from the surveys was also codified). Ages ranged from 19 to more than 25, with the average over 22.875. From the American section, 35 students participated - 12 who took at least 1 online course and 23 who never took an online course (traditional FTF). The data was entered into an EXCEL spreadsheet for preliminary analysis.
\end{abstract}

\title{
Overall Comparison Online vs. Traditional Student Perceptions
}

As shown in Table 1, Section A, online international students prefer to be in a FTF class instead of OL. Student preferences also indicate a slight dislike toward online learning versus FTF learning for difficulty, motivation, student interaction, instructor interaction, self-directed, and independence. Students indicate they perceived cheating to be more likely in online classes than FTF. Online students are indifferent to the discipline between the two environments, time and cost investment, and happiness with the OL environment. Online students find the schedule flexibility to be slightly positive. Unfortunately, all online participants only took 1 online course, and did not take a preparation course prior to the online course. Correspondingly, in Section B, traditional students indicate that they were happy with the FTF classroom and prefer it. Traditional students perceive the FTF classroom to be slightly less difficult and independent than OL. They are more motivated, approved of the selfdirected learning environment, prefer the interaction with students and the instructor. They also feel cheating is more difficult in the traditional environment than online. Traditional students enjoy the discipline of the 
FTF environment. However, traditional FTF students note the schedule flexibility associated with OL over FTF. They feel that FTF costs slightly more and requires slightly more time than OL. The majority of both FTF and OL students indicate that online courses are appropriate at the University.

As shown in Table 2, tests for significant differences in perceptions between the online students and traditional FTF students (t-test, 2tails, assuming heteroscedasticity) reveal that the groups significantly differ in their perceptions on many measures. Both groups favor the traditional FTF environment for motivation $(\mathrm{p}=.01)$, interaction with students $(\mathrm{p}=.03)$, and interaction with the instructor $(\mathrm{p}=.00)$. Similarly, both groups perceive cheating to be more difficult in the FTF environment $(\mathrm{p}=.04)$. They also prefer the self-directed FTF environment more $(\mathrm{p}=.03)$. However, both groups note the schedule flexibility associated with OL courses over FTF ( $p=.09)$. While the OL students are indifferent to the investment costs, FTF student feel traditional courses cost more than OL $(\mathrm{p}=.01)$. Both groups prefer the traditional classroom over online $(\mathrm{p}=.00)$. While online students appear to be indifferent, traditional students prefer to be in a traditional classroom $(\mathrm{p}=.03)$. The majority of OL students would prefer to be in a traditional classroom, while only 2 of 16 traditional students would prefer to be online. Perhaps the online students do not have enough experience in the online environment to prefer it. Both groups are indifferent with respect to difficulty $(\mathrm{p}=.87)$, discipline $(\mathrm{p}=.33)$, independence $(\mathrm{p}=.88)$, time investment $(\mathrm{p}=.67)$, and feel online courses are appropriate at the University $(\mathrm{p}=.23)$.

\section{International Comparison}

Due to the low participation rate to date, the international comparison is only preliminary as it lacks adequate statistical participation for a country-by-country comparison. As shown in Table 4, comparison of the international group to the domestic (American) students did not reveal any significant differences between the OL and traditional FTF groups in their perspectives for most categories with the exception of cost 
investment $(\mathrm{p}=.02)$ and preference $(\mathrm{p}=.01)$ for the OL group. Americans tend to feel that OL courses cost less than their international counterparts as shown in Table 3. Interestingly, Americans are more indifferent to the two environments than their international counterparts, who would definitely prefer to be in a traditional classroom.

To gather further insight into student perceptions, the intent of the study was to compare various countries perspectives. However, due to the low enrollment to date, comparison by region of the world - Africa (Nigeria), Americans, Europe (Belgium, France, Germany, Serbia, and Ukraine), Far East (China, Japan and Korea) and Middle East (Saudi Arabia) was completed instead. Three Africans, 35 Americans, 5 Europeans, 6 students from the Far East, and 3 students from the Middle East completed the survey. Results are shown in Table 5. All of the Africans, Americans included here, and Europeans only experienced FTF classrooms. Half of the other two populations experienced each type of classroom. Given the small participation numbers, the only populations that can be compared are the FTF perspectives of the Africans (Nigerians), Americans, Europeans, and half of the population from the Far East (Japan and Korea). The only significant factor was the difference between the African and Far Eastern perspectives with respect to difficulty $(\mathrm{p}=.04)$, where the Africans felt the FTF classroom was significantly easier (than OL) than the Far Easterners, who felt the online environment was slightly easier (See Table 6). With respect to comparison with the Americans, no significant differences emerged. However, slight significance was noted for difficulty $(\mathrm{p}=.09)$ and happiness $(\mathrm{p}=.09)$ with the Far Easterners, and for independence $(\mathrm{p}=.06)$ and schedule flexibility $(\mathrm{p}=.06)$ with the Europeans.

\section{Learning Experience Preferences}

When analyzing the learning experiences preferences, OL international students prefer reading (33.33\%), homework (30\%), and videos $(20 \%)$. However, they dislike working with other students and problem scaffolding and hints as shown in Table 7. Traditional FTF students prefer instructor lectures (19.61\%), in-class sessions (13.73\%) and working with 
other students (13.73\%). Perhaps, traditional students find the interaction with others as the key reason to be in a traditional class versus online. Comparing preferences of the two populations, online students appear to favor different activities than FTF students, who prefer in-class sessions and instructor lectures.

\section{Online Perceptual Differences with Experience}

To date, international students took only one course and comparison between perspectives when students experience more online courses cannot be done.

\section{Undergraduates vs. Graduates}

For the preliminary analysis, three undergraduates and 3 graduates took online courses, while 8 undergraduates and 3 graduates have not taken an online course. As shown in Table 8, there are no significant differences between undergraduates and graduates with respect to their responses to either the online or traditional environment.

\section{Analysis by Age}

Given the current participation, we are unable to analyze and comment on whether student age has an impact. Currently, online participants include 2-20 year olds, 123 year old, 125 year old, and 1 more than 25 . Traditional FTF students include 1 - 19 year old, 1-20 year old, 2-21 year olds, 3- 23 year olds, 1-24 year old, and 4 students more than 25.

\section{Gender}

Currently, 4 females and 2 males completed the online perspectives, while 8 females and 4 males completed the traditional FTF survey. The only significant difference was for time investment for the OL group. Females (2.75) tended to indicate slightly less time OL than FTF, where males (4.0) indicate they spend more time in an OL course than FTF $(p=.02)$. Slightly significant factors were noted for cheating in the OL environment $(\mathrm{p}=.06)$ and in the FTF environment, student interaction 
$(\mathrm{p}=.09)$. Females (2.25) indicate that it's easier to cheat OL than FTF while males are indifferent (3.0). In the FTF environment, females (4.25) like the interaction with others slightly more than males (3.5).

\section{DISCUSSION}

Our study looks to evaluate the differences in international student perceptions of OL and FTF education. Currently, while only a few international students participated, the results offer some insight into student perceptions. We continue with a discussion of the student characteristic and program characteristic factors that may impact upon student perceptions.

\section{Student Characteristics}

Undoubtable, student satisfaction is partially a function of the student characteristics in the OL or FTF course. International student characteristic differences with respect to their perceptions of OL versus FTF education do not appear to be significantly different than results uncovered in our previous study (Fish \& Snodgrass, 2014). Specifically:

Age. Due to low participation, we are unable to prove or disprove age as a student factor at this time.

Major/Level. Similar to our previous study (Fish \& Snodgrass, 2014), there were no significant differences between undergraduates and graduates with respect to their responses to either the online or traditional environment. This insignificance does not support previous studies (Tanner et al., 2004-1; 20004-2; Billings, Skiba \& Connors, 2005; Dobbs et al., 2009); however, these studies are several years old.

Gender. At a summary level, no overall differences between men and women appear to exist with respect to their perceptions of online and traditional FTF learning environments in support of several previous studies (Tanner et al., 2003; Fish \& Snodgrass, 2014). These results contrast Hofsted's (1986) premise; however, this result should be viewed 
cautiously as it may prove differently when more data is gathered that may be divided by different cultures differently.

Previous Experience. At this time, since every OL participant only took $1 \mathrm{OL}$ course, its impossible to test the differences in perspectives with experience.

Student Motivation and Commitment. Motivation was not significantly different by culture, contrasting other studies (Kearlsey, 1996); however, both OL and FTF students felt they were motivated more in the FTF environment. This result is in keeping with our previous study (Fish \& Snodgrass, 201). Culturally, Americans are more indifferent to the two environments than their international counterparts, who would definitely prefer to be in a traditional classroom. Perhaps this is due to the fact that the international students were participating in OL courses in a different language than their native one. Time investment was not significantly different between different regions, between OL and FTF, or between International and Americans, in support of our previous results (Fish \& Snodgrass, 2014). It appears that the time zone differences do not appear to be an additional burden to OL students.

Cultural Student Differences. Both the OL and FTF students favor the interaction with others and the instructor in a traditional classroom. Differences between different cultures were not detected. which does not support other studies (Liang \& McQueen, 1999). While independent work was insignificant between OL and FTF, and most of the regions, Americans preferred the independent work of FTF slightly more than their European counterparts. International students prefer to be in a FTF environment more than their American counterparts. Perhaps this is due to enrollment in an American University and the International student may wish to participate in the culture more directly.

\section{Program Characteristics}

While student characteristics impact upon student perceptions, program characteristics also impact upon the learning experience. Online 
education brings additional barriers to the educational process such as time constraints, lack of technological skills, and low interactivity with the communication process. These barriers may positively or negatively impact upon a students' perception of their academic experience. In most instances, the results of this study yield similar results to our previous study (Fish \& Snodgrass, 2014).

Cultural Program Issues. In spite of Hofstede's framework (1986) and several other studies comparing different types of societies and learning styles (Lin et al., 2010; Hornik \& Tupchiy, 2006; Collis, 1999), given the current international population with their diverse backgrounds, the students prefer the FTF environment over OL. However, this result should be viewed cautiously due to the small population surveyed. The American, individualistic, process-oriented students did not appear to be significantly different than the International, collective, Easternsociety students. Africans find OL courses to be significantly easier than Middle Eastern students. Once additional surveys are gathered, the course difficulty appears to be a factor that may prove to be significantly different between different cultures as many results show a mild significance. This contrasted other studies (Lee et al., 2012; Liu et al., 2010). However, since this study only included students with 1 OL experience, perhaps students did not pick up on the salient differences as they will upon taking more courses.

Course Organization. Flexibility and convenience are the most common reasons students indicate as to why they take online courses (Armstrong, 2011; Horspool \& Lange, 2012; Leasure et al., 2000; Perreault et al., 2008). Both international OL and FTF groups perceive OL as being more flexible, but prefer the self-directed nature of the FTF classroom over OL, which support several studies on course organization (Armstrong, 2011; Merisotis \& Olsen, 2000; Perreault et al., 2008). While most categories (motivation, , discipline, and self-directed) were indifferent between the various regions, differences may be significant with regard to course difficulty and independence as additional survey information is added. 
Academic Rigor. Since several regional comparisons (e.g., Africa versus Far East and Africa versus Europe) show mild significance for course difficulty, different cultures may view OL and FTF academic rigor differently than others. However, in our study, Nigerians perceive the OL environment to be easier than FTF, contrasting a previous study on sub-Sahara Ghana where students perceived collaborative online learning as complex, more demanding and time-consuming than in a FTF environment (Asunka, 2008). Obvious this result highlights differences within world regions with respect to perceptions.

Program Quality. The majority of participants favor the FTF environment over the OL environment - regardless of whether the student has taken an online course, took traditional FTF courses, was an international or domestic student. This contrasts chief academic officers perceptions (Allen \& Seaman, 2013; Fjermestad, Hiltz, \& Zhang, 2005; Hannay \& Newvine, 2006; Parker, 2003) but supports other studies (in Ghana) indicating the opposite as students held the view that online learning offered no advantage over FTF (Asunka, 2008). When faculty are perceived as missing from the educational conversation as in the favoring of FTF over OL demonstrated by international students in this study, students may perceived the course quality as poor (Armstrong, 2011).

Academic Integrity. Both international and domestic, whether OL and FTF, students feel that it is easier to cheat in the OL environment and supports the criminal justice study (Lanier, 2006) as well as our previous study (Fish \& Snodgrass, 2014). This belief was not significantly different between regions.

Communication Mechanisms. Communication is shaping students' perceptions and approaches to learning as communication speed and consistency are relevant (Armstrong, 2011). International students favor the interaction with students and their instructor in the FTF environment, similar to our previous study (Fish \& Snodgrass, 2014). Again, these results support several other studies that indicate online communication issues with other students (Horspool \& Lange, 2012; Dirkx \& Smith, 
2004; Maeroff, 2004). These perceptions were not significantly different across different regions.

Faculty Involvement. International students favor the interaction with their instructor in the FTF environment, and differences between different regions in this perception are not apparent. This result supports our previous study (Fish \& Snodgrass, 2014) as well as others (Wuensch, Aziz, Ozan, Kishore \& Tabrizi, 2008; Wang \& Morgan, 2008), but contrasts some studies that favor OL interaction with the instructor (Boyd, 2008).

Technologies. OL international students appear to prefer independent activities, such as reading, homework and videos, while international FTF students tend to prefer instructor lectures, in-class sessions and working with other students. Obviously, OL students prefer independent activities that do not require working with others, which requires little communication in the OL environment, while FTF students prefer working with others through interacting with others in person. The international preferences are similar to our previous study (Fish \& Snodgrass, 2014) where OL student preferred homework, discussions and videos as adding the most to their educational experience, and felt instructor lectures and inclass sessions decreased their understanding. Similar to our other study, international FTF students perceived instructor lectures, interaction with others and in-class sessions increased their academic understanding (Fish \& Snodgrass, 2014).

\section{CONCLUSIONS}

Clearly, international and domestic students in our studies favor FTF education over OL.

While international and domestic, online and traditional students indicate that online courses are appropriate at the University, they prefer to be in a traditional classroom. In spite of a preference for traditional classes, students who chose to take online courses appear to take the courses mainly for requirement or flexibility reasons (Appendix B). Also 
noteworthy is the fact that the current OL students surveyed only took 1 course, which may be a significant factor in their perceptions.For almost every factor studied (difficulty, motivation, interaction with students, interaction with instructors, discipline, cheating, self-directed, independence, schedule flexibility, time and cost investment), along with their comments regarding taking online courses (Appendix B), traditional students appear to know their learning style and understand their personal need for FTF interaction. The end result may be selfselection by students to the learning environment that suits their needs best. So while many online advocates point to the increasing desire for online classes (Allen \& Seaman, 2013), these results indicate that this may not be the case for students with different learning styles or universities with differing student populations. Several online perception studies were done at large, universities or in a public forum (Horspool \& Lange, 2012; Tanner et al., 2003; Tanner et al., 2004-1; 2004-2; Tanner et al, 2006; Tanner et al, 2009) or in non-business fields (e.g. Dobbs et al, 2009; Lanier, 2006; Leasure et al, 2000; Reilly et al., 2012; Tekinarslan, 2011; Wang \& Morgan, 2008). The context of what the University has to offer in the FTF classroom may be an important construct for administrators to consider in their framework for online course development. In a similar vein, and in support of previous research (Dobbs et al., 2009), the significant perceptual differences between the students who have and those who have not experienced online education exist.

Previous research supports the result that as students take more online courses, their perceptions of this academic method improve (Dobbs et al., 2009; Mortagy \& Boghikian-Whitby, 2010; Perreault et al., 2008). Perhaps, since all of the students in this study only took 1 online course, the students may not have enough experience to adjust to the online environment, and therefore, still prefer the traditional classroom over online courses.

With respect to learning experiences at the teaching University, international online and traditional students favor different learning 


\section{The BRC Academy Journal of Business Vol. 5, No. 1}

techniques. Again, this result has implications for both the online and traditional instructor as well as administrators in developing their online and FTF frameworks. The University prides itself on and markets its teaching atmosphere. Students who chose to study at the University in the traditional classroom clearly value the interaction with the instructor and other students in the classroom. However, in the online environment, these same students prefer the reading, homework, and videos over the more traditional in-class sessions, instructor lectures and other students. Obviously, students favor different teaching methods in each teaching medium.

If one assumes as upper administrators do that online education is equivalent to FTF (Allen \& Seamen, 2013), then students should be indifferent to all of the factors surveyed. The results clearly indicate that this is not the case as international students at a teaching university preferred FTF education. In general, these results support one study while contrasting another for every factor studied. Evidently, other factors exist that impact upon students' perceptions regarding online education. Research to uncover these underlying factors is needed. Other potential factors such as exploring student learning styles or university contextual factors of size and focus (teaching versus research) may offer a clearly understanding of student perceptions of online education.

\section{LiMITATIONS}

Obviously the small participation in the survey is an issue that needs attention. Over the next few months, additional participation of the international student body will be sought. The small participation is greatly limiting cultural comparisons.

\section{Future Research}

Several areas for future research exist including: student learning styles and specific university contextual comparisons, a deeper comparison of 
teaching populations, and course design. While the discussion highlights the potential for differences due to contextual factors of a teaching university versus larger research universities, a specific study directly comparing business students at one type versus another is lacking. Also, current research does not differentiate between for-profit and notfor-profit institutions of higher education. As the number of students taking more online classes increases, comparisons to the FTF classes in perceptions may be evaluated in finer detail. The current curriculum includes part-time students, full-time students and online students. Differences in student perceptions between each of these groups may be explored in greater detail. There are significant differences in course design between online and FTF education, and these differences need to be evaluated as well. Hence, much work remains in this constantly changing area of student online perceptions.

\section{REFERENCES}

Allen, I., \& Seaman, J. (2013). Changing Course: Ten Years of Tracking Online Education in the United States. The Sloan Consortium (SloanC), Retrieved on January 11, 2013 from http://sloanconsortium.org/ publications/survey/making_the_grade_2006

Armstrong, D.A. (2011). Students' Perceptions of Online Learning and Instructional Tools: A Qualitative Study of Undergraduate Students Use of Online Tools. The Turkish Online fournal of Educational Technology - July 2011, 10(3), 222-226.

Asunka, S. (2008). Online Learning in Higher Education in Sub-Saharan Africa: Ghanaian University students' experiences and perceptions. International Review of Research in Open and Distance Learning, October 2008, 9(3), 1-23.

Bejerano, A.R. (2008). Raising the Question \#11 The Genesis and Evolution of Online Degree Programs: Who Are They For and What Have We Lost Along the Way? Communication Education, 57(3), 408-414. http:// dx.doi.org/10.1080/03634520801993697

Billings, D.M., Skiba, D.J. \& Connors, H.R. (2005). Best Practices in Webbased Courses: Generational Differences Across Undergraduate and 
Graduate Nursing Students. Journal of Professional Nursing, 21(2), 126-133. http://dx.doi.org/10.1016/j.profnurs.2005.01.002

Boyd, P.W. (2008). Analyzing students' perceptions of their learning in online and hybrid first year composition courses. Computers and Composition, 25, 224-43. http://dx.doi.org/10.1016/j.compcom.2008. 01.002

Carr, S. (2000). As distance education comes of age, the challenge is keeping the students. Chronicle of Higher Education, 46(23), A39.

Collis, B. (1999). Designing for differences: Cultural issues in the design of WWW-based course-support sites. British fournal of Educational Technology, 30(3), 201-215. http://dx.doi.org/10.1111/1467-8535.00110

Connolly, T.M., MacArthur, E., Stansfield, M. \& McLellan, E. (2007). A quasi-experimental study of three online learning courses in computing. Computers \& Education, 49, 345-59. http://dx.doi.org/10 .1016/j.compedu.2005.09.001

Dirkx, J. M., \& Smith, R. O. (2004). Thinking out of a bowl of spaghetti: Learning to learn in online collaborative groups. In T. S. Roberts (Ed.), Online collaborative learning: Theory and practice, Hershey, PA: Information Science Publishing, 132-159.

Dobbs, R., Waid, C.A., \& del Carmen, A. (2009). Students' Perceptions of Online Courses: The Effect of Online Course Experience. Quarterly Review of Distance Education, Spring 2009, 10(1), 9-26.

Fish, L.A. and Snodgrass, C.R. (2014; InPress). A Preliminary Study of Business Student Perceptions of Online versus Face-to-Face Education. Fournal of Advances in Education.

Fjermestad, J., Hiltz, S. R., \& Zhang, Y. (2005). Effectiveness for students: Comparisons of "inseat" and ALN courses. In S. R. Hiltz \& R. Goldman (Eds.), Learning together online: Research on asynchronous learning networks, Mahwah, NJ: Lawrence Erlbaum, 39-80.

Fowler, D. (2005). Are on-site courses as effective as online? Online Cl@ssroom: Ideas for Effective Online Instruction, March, 1-2.

Fredericksen, E., Pickett, A., Shea, P., Pelz, W., \& Swan, K. (2000). Student satisfaction and perceived learning with online courses: Principles 
and examples from the SUNY learning network. Journal of Asynchronous Learning Networks, 4(2), 7-41.

Hannay, M., \& Newvine, T. (2006). Perceptions of Distance-Learning: A Comparison of Online and Traditional Learning. MERLOT fournal of Online Learning and Teaching, 2(1), 1-11, Accessed on January 11, 2013 from http://jolt.merlot.org/documents/MS05011.pdf

Hara, N., \& Kling, R. (2003). Students' distress with a web-based distance education course: An ethnographic study of participants' experiences. Turkish Online fournal of Distance Education, 4(2), 557-579.

Henderson, L. (1996). Instructional design of interactive multimedia. Educational Technology Research and Development, 44(4), 85-104. http://dx.doi.org/10.1007/BF02299823

Hofstede, G. (1986). Cultural differences in teaching and learning. International fournal of Intercultural Relations, 10, 301-320. http://dx. doi.org/10.1016/0147-1767(86)90015-5

Hornik, S., \& Tupchiy, A. (2006). Culture's impact on technology mediated learning: The role of horizontal and vertical individualism and collectivism. Journal of Global Information Management. 14(4), 31-56. http://dx.doi.org/10.4018/jgim.2006100102

Horspool, A. \& Lange, C. (2012) Applying the scholarship of teaching and learning: student perceptions, behaviors and success online and face-to-face, Assessment \& Evaluation in Higher Education, February 2012, 37(1), 73-88. http://dx.doi.org/10.1080/02602938.2010.496532.

Kenny, J. (2003). Student perceptions of the use of online learning technology in their courses. ultiBASE Articles. Accessed on January 9, 2013 from http://ultibase.rmit.edu.au/Articles/march03/kenny2.pdf

Ku, H. \& Lohr, L. L. (2003). A case study of Chinese students' attitude toward their first online learning experience. Education Technology Research and Development,51(3), 94-102. http://dx.doi.org/10.1007/ BF02504557

Lanier, M. (2006). Academic Integrity and Distance Learning. Fournal of Criminal fustice Education, Sep 2006, 17(2), 244-21. http://dx.doi. org/10.1080/10511250600866166 
Leasure, A. R., Davis, L., \& Thievon, S. L. (2000). Comparison of student outcomes and preferences in a traditional vs. World Wide Web-based baccalaureate nursing research course. Fournal of Nursing Education, 39(4), 149-154.

Lee, J.W., Becker, K. \& Nobre, H. (2012). Impact of culture on online management education. Cross Cultural Management, 19(3), 399-420. http://dx.doi.org/10.1108/13527601211247116

Liang, A. \& McQueen, R.J. (1999). Computer assisted adult interactive learning in a multi-cultural environment. Adult Learning, 11(1), 26-29.

Lin, X,.Liu, S., Lee, S. \& Magjuka, R.J. (2010). Cultural Differences in Online Learning: International Student Perceptions. Educational Technology \& Society, 13(3), 177-188.

Maeroff, G. I. (2004). Classroom of one: How online learning is changing our schools and colleges. Gordonsville, VA: Palgrave Macmillan.

Maltby, J. R., \& Whittle, J. (2000). Learning programming online: Student perceptions and performance. Proceedings of the ASCILITE 2000 Conference. Accessed on January 9, 2013 from http://www.ascilite. org.au/conferences/coffs00/papers/john_maltby.pdf

McLoughlin, C. \& Oliver, R. (2000). Designing learning environments for cultural inclusivity: A case study of indigenous on-line learning at tertiary level. Australian fournal of Educational Technology, 16(1), 58-72.

Merisotis, J. P., \& Olsen, J. K. (2000). The 'effectiveness' debate: What we know about the quality of distance learning in the US. TechKnowlogia, 2(1), 42-44.

Mortagy, Y. \& Boghikian-Whitby, S. (2010). A Longitudinal Comparative Study of Student Perceptions in Online Education. Interdisciplinary fournal of E-Learning and Learning Objects, 6, 23-46.

Mullen, G.E., \& Tallent-Runnels, M.K. (2006). Student outcomes and perceptions of instructors' demands and support in online and traditional classrooms. Internet and Higher Education, 9, 257-66. http:// dx.doi.org/10.1016/j.iheduc.2006.08.005 
Olesova, L., Yang, D. \& Richardson, J.C. (2011). Cross-cultural differences in Undergraduate Students' Perceptions of Online Barriers. Fournal of Asynchronous Learning Networks, 15(3), 68-80.

Palmer, S. \& Holt, D. (2010). Students' perceptions of the value of the elements of an online learning environment: looking back in moving forward. Interactive Learning Environments, June 2010, 18(2), 135-151. http://dx.doi.org/10.1080/09539960802364592

Parker, M. (2003). Technology-enhanced e-Learning: Perceptions of First Year Information Systems Students at the Cape Technikon. Proceedings of the South African Institute of Computer Scientists and Information Technologists, SAICSIT 2003, 316-319.

Perreault, H., Waldman, L., Alexander, M. \& Zhao, J. (2008). Graduate Business Students' Perceptions of Online Learning: A Five Year Comparison. The Delta Pi Epsilon Journal,Fall 2008, L(3), 164-179.

Picciano, A. (2002). Beyond Student Perceptions: Issues of Interaction, Presence, and Performance In An Online Course. Journal of Asynchronous Learning Networks, 6(1), 21-40.

Reilly, J.R., Gallager-Lepak, S. \& Killion, C. (2012). Me and My Computer: Emotional Factors in Online Learning, Nursing Education Perspectives, March/April, 33(2), 100 - 105.

Richardson, J., \& Swan, K. (2003). Examining Social Presence In Online Courses In Relation to Students' Perceived Learning and Satisfaction. fournal of Asynchronous Learning Networks, 7(1), 68-88.

Sener, J., \& Stover, M. L. (2000). Integrating ALN into an independent study distance education program: NVCC case studies. Fournal of Asynchronous Learning Networks, 4(2), 126-144.

Song, L., Singleton, E., Hill, J., \& Koh, M. (2004). Improving Online Learning: Student Perceptions and Challenging Characteristics. Internet and Higher Education, 7, 59-70. http://dx.doi.org/10.1016/j. iheduc.2003.11.003

Stodel, E. J., Thompson, T. L., \& MacDonald, C. J. (2006). Learners' perspectives on what is missing from online learning: Interpretations through the community of inquiry framework. International Review of Research in Open and Distance Learning, 7(3), 1-24. Accessed on 
January 9, 2013 from http://www.irrodl.org/index.php/irrodl/article/ view/325/743

Tanner, J.R., Noser, T.C., \& Totaro, M.W. (2009). Business Faculty and Undergraduate Students' Perceptions of Online Learning: A Comparative Study. Journal of Information Systems Education, Spring 2009, 20(1), 29-40.

Tanner, J., Noser, T., Totaro, M., \& Birch, R. (2006). Student Perceptions of The Online 'Classroom': An Update. International Business \& Economics Research fournal, 5(10), 31-38.

Tanner, J., Noser, T., Fuselier, J., \& Totaro, M. (2004-1). 'The Online 'Classroom': Differences in Perception between Business Students and Non-Business Students. Fournal of College Teaching and Learning, 1(3), 37-44.

Tanner, J., Noser, T., Fuselier, J., \& Totaro, M. (2004-2), 'The Online 'Classroom': What Do Students Think? Journal of Informatics Education Research, 6 (1), 43-54.

Tanner, J., Noser, T., \& Langford, H. (2003). Perceptions of Undergraduate Business Students Toward Online Courses In Higher Education Expanded and Revisited: Do Gender, Age, and/or Past Experiences Make a Difference? Journal of Business and Economics Research, 1(2), 13-20.

Tekinarslan, E. (2011). Faculty of Education Students' Self-efficacy Perceptions toward Online Technologies. Electronic fournal of Social Sciences, Summer 2011, 10(37), 120-134.

Thompson, L. \& Ku, H. (2005). Chinese graduate students' experiences and attitudes toward online learning. Educational Media International, 42(1), 33-47. http://dx.doi.org/10.1080/09523980500116878

Topper, A. (2007). Are they the same? Comparing the instructional quality of online and face-to-face graduate education courses. Assessment \& Evaluation in Higher Education, 32 (6), 681-691. http://dx.doi.org/1 0.1080/02602930601117233

Wang, L.C. \& Morgan, W.R. (2008). Student Perceptions of Using Instant Messaging Software to Facilitate Synchronous Online Class Interac- 
tion in a Graduate Teacher Education Course. Journal of Computing in Teacher Education, Fall 2008, 25(1), 15-21.

Wuensch, K.L., Aziz, S., Ozan, E., Kishore, M. \& Tabrizi, M.H. (2008). Pedagogical characteristics of online and face-to-face classes. International fournal on E-Learning, 7(3), 523-32.

Zhang, J. (2007). A cultural look at information and communication technologies in Eastern education. Education Technology Research and Development, 55(3), 301-314. http://dx.doi.org/10.1007/s11423-0 07-9040-y

\section{Web Appendix}

A web appendix for this paper is available at:

http://dx.doi.org/10.15239/j.brcacadjb.2015.04.01.wa04

\section{Citation Information}

Fish, Lynn A. and Coral R. Snodgrass. "A Preliminary Study of International Student Perceptions of Online versus Face-to-Face Education.” The BRC Academy Journal of Business 5, no. 1 (2015): 67-99. http:// dx.doi.org/10.15239/j.brcacadjb.2015.04.01.ja04 